\title{
Dissimilar welding of high-entropy alloy to Inconel 718 superalloy for structural applications
}

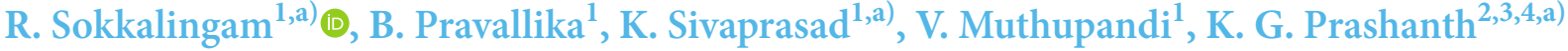 \\ ${ }^{1}$ Advanced Materials Processing Laboratory, Department of Metallurgical and Materials Engineering, National Institute of Technology, \\ Tiruchirappalli, Tamil Nadu 620015, India \\ ${ }^{2}$ Department of Mechanical and Industrial Engineering, Tallinn University of Technology, Ehitajate tee 5, 19086 Tallinn, Estonia \\ ${ }^{3}$ Erich Schmid Institute of Materials Science, Austrian Academy of Sciences, Jahnstraße 12, 8700 Leoben, Austria \\ ${ }^{4}$ CBCMT, School of Mechanical Engineering, Vellore Institute of Technology, Vellore 632014, India \\ a) Address all correspondence to these authors. e-mails: sokkalingam.rathinavelu@gmail.com; ksp@nitt.edu; kgprashanth@gmail.com \\ Received: 31 May 2021; accepted: 12 August 2021; published online: 22 October 2021
}

High-entropy alloy, a new generation material, exhibits superior structural properties. For hightemperature applications, where dissimilar materials are in demand, HEAs may be joined with commercially available structural materials to improve their performance-life ratio. In this connection, a dissimilar joint was fabricated by gas tungsten arc welding between $\mathrm{Al}_{0.1} \mathrm{CoCrFeNi-HEA}$ and Inconel 718. The columnar dendritic grains are growing epitaxially at the $\mathrm{Al}_{0.1} \mathrm{CoCrFeNi-HEA/weld} \mathrm{metal}$ interface, where their compositions are matching. While the composition misfit at the weld metal/ Inconel $\mathbf{7 1 8}$ interface, reveals the non-epitaxial mode of solidification. In addition, the fusion zone exhibits the porosity and micro-segregation of $\mathrm{NbC}$ and Laves phases. The joint shows a joint efficiency of $\sim 88 \%$, where the strength is observed to be $644 \mathrm{MPa}$ with $21 \%$ ductility. The results demonstrate the applicability of GTAW in fabricating the dissimilar weld joints between HEA and Inconel 718 for structural applications.

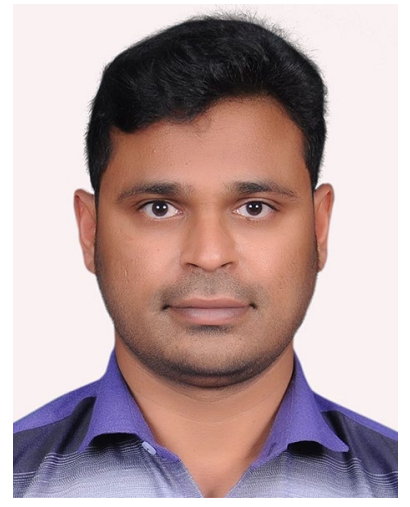

Dr. R. Sokkalingam received his Ph.D. in Metallurgical and Materials Engineering in 2020 from National Institute of Technology Tiruchirappalli, India under the guidance of Drs. K. Sivaprasad and V. Muthupandi. His Ph.D. research was on "Welding and Additive Manufacturing of High Entropy Alloys: Structure-Property Correlation”. His research interests include (i) welding technology, (ii) metal additive manufacturing, (iii) high entropy alloys, (iv) powder metallurgy, (v) Functionally graded materials, (vi) metal matrix composites, and (vii) processstructure-property correlations.

Dr. R. Sokkalingam

\section{Introduction}

A novel alloy design concept proposed independently by two eminent scientific teams of Yeh and his coworkers [1] and Cantor and coworkers [2] led to the discovery of high-entropy alloys (HEAs). HEA is a random substitutional solid solution comprising of multiple principal metallic components $[1,2]$. The traditional alloying concept strongly believes in the formation of complex intermetallic compounds during multiple principal alloying. However, 1 HEAs exhibit simple microstructure/crystal structures [3]. High specific strength, high thermal stability, remarkable wear resistance, and high oxidation resistance over a wide range of temperatures from cryogenic temperature to high temperatures are observed in HEAs [4-6]. The sluggish cooperative diffusion of principal alloying elements in HEAs 
and the severe lattice distortion due to the mixing of atoms with the varying atomic radii attributes to the structural stability and improved mechanical properties [7].

$\mathrm{Al}_{0.1} \mathrm{CoCrFeNi}-\mathrm{HEA}$ is one of the most examined HEAs, which exhibit simple solid solution with FCC crystal structure with excellent mechanical properties [8]. Wang et al. have found that $\mathrm{Al}_{0.1} \mathrm{CoCrFeNi}$-HEAs show better-softening resistance than the Ni-based superalloys (IN718 and IN718H) at high temperatures [9]. Li and Zhang have reported that the formation of nano-mechanical twinning during deformation results in higher tensile strength and Charpy impact toughness in $\mathrm{Al}_{0.1}$ CoCrFeNi-HEA both at room (635 $\mathrm{MPa}$ and $420 \mathrm{~J}$ ) and cryogenic (1042 $\mathrm{MPa}$ and $289 \mathrm{~J}$ ) temperatures than that of conventional steels [10]. Kumar et al. have demonstrated a high strain rate sensitivity and work hardening ability in $\mathrm{Al}_{0.1} \mathrm{CoCrFeNi}$-HEA using Split-Hopkinson pressure bar at $\sim 1000 /$ s and $\sim 2600 /$ s when compared to AISI304 stainless steel and IN718 alloys in quasi-static conditions $\left(10^{-3} \mathrm{~s}^{-1}\right.$, $10^{-2} \mathrm{~s}^{-1}$, and $10^{-1} \mathrm{~s}^{-1}$ ) [11]. Due to this exceptional mechanical properties, $\mathrm{Al}_{0.1} \mathrm{CoCrFeNi}$-HEAs is believed to be a substitute to the currently available commercial high-temperature alloys in some critical high-temperature applications [12].

As welding is a prime fabrication process for manufacturing huge structures in aerospace, automobile, power plants and chemical industry applications, weldability studies on HEA is necessary to make sure its applicability [12-15]. Some preliminary weldability studies have already been conducted on the similar welding of CoCrFeNiMn-HEA [16] and $\mathrm{Al}_{\mathrm{x}} \mathrm{CoCrFeNi}$ HEAs [17-22]. Overall reviews suggest that the CoCrFeMnNi-HEA and $\mathrm{Al}_{(\mathrm{x}=0-0.6)} \mathrm{CoCrFeNi-HEAs}$ are weldable, while $\mathrm{Al}_{(\mathrm{x}>0.6)} \mathrm{CoCrFeNi-HEAs} \mathrm{are} \mathrm{susceptible}$ to solidification cracking. However, fabrication of structural parts sometimes requires dissimilar welding (DW) between different alloys to make the design simpler (and to reduce the cost), especially when the structures are exposed to varying service conditions [23-25]. Hence study on dissimilar welding between HEA and commercially available structural alloys (stainless steels, nickel-base superalloys, titanium alloys, etc.,) is vital for preparing most economic and reliable structures. Generally, localized abnormal thermal cycles and subsequent fast cooling rates during welding could change the microstructure and the composition locally [26]; hence, the mechanical and electrochemical properties of the weld joint could vary from that of base materials. Further, DW could result in the formation of hard and brittle intermetallic compounds especially when welded autogenously [26]. Nam et al. has welded HEAs with different processing conditions (as-cast and as-rolled conditions) by laser welding and found evolution of columnar dentritic grains epitaxially and strength of the dissimilar weld joint is comparable with the as-cast HEA as it fails at as-cast HEA [27]. Sokkalingam et al. have examined dissimilar weld joint between $\mathrm{Al}_{0.1} \mathrm{CoCrFeNi}$-HEA and AISI304 stainless steel by gas tungsten arc welding (GTAW) [28] and electron beam welding (EBW) [29] processes. Both joints show evolution of columnar grains from the weld interfaces with formation of unmixed zone at the AISI304 stainless steel side. Further the joint prepared with GTAW has shown transition from columnar grains to equiaxed grains, while that prepared by EBW shows only columnar grains due to narrow weld bead size. Bridges et al. have laser brazed Inconel 718 alloy with $\mathrm{NiMnFeCoCu}-\mathrm{HEA}$ and found that the bonding strength is good when brazing temperature is below the liquidus temperature [30]. However, dissimilar joining of HEA with Inconel 718 with scope of introducing HEA as structural material is not available in the literature so far. Hence, with the view of using HEA in high-temperature structural applications like aero-engine structural components, an investigation has made on the dissimilar joint fabricated between high-entropy alloy and Ni-based superalloy (i.e., Inconel 718) by gas tungsten arc (GTA) welding process. Further, the study mostly focuses on the microstructure evolution and the resultant mechanical properties changes.

\section{Results and discussion}

\section{Macrostructure}

The macrostructures of the weldment are given in Fig. 1 a and b. The photograph of the rear side of the fabricated joint is also presented as an inset in Fig. 1b. These figures ascertain that the chosen GTAW parameters enabled the production of a dissimilar autogenous butt joint with full penetration in a single pass. Small pores with an average size of $\sim 20 \mu \mathrm{m}$ are observed in the weld fusion zone (Fig. 1b). Other than this, the weld does not show the presence of any weldability issues like the solidification cracking and heat-affected zone (HAZ) cracking. The highlighted regions (marked by the rectangles) in Fig. 1b were studied to analyze the evolution of the micro-texture and microstructure along the weldment. As the weld bead is wider due to higher heat input imparted during the GTA welding process, the EBSD scanning was executed in two halves, as shown in Fig. 1c-f. As observed by Eghlimi et al. [31] and Chu et al. [32], the weldment in the present work also reveals the presence of varying microstructures and micro-textures in the different regions (base metals, BMs and fusion zone, FZ). Like typical welds, this dissimilar weld joint (DW) is also characterized by regions such as FZ, HAZ, and BMs with distinct microstructures and clear delineating interfaces on both sides. X-ray diffraction (XRD) patterns have been extracted from different regions of the weldment say base metals (IN718 and HEA) and the weld fusion zone for the phase identification as in Fig. 2. The grain 


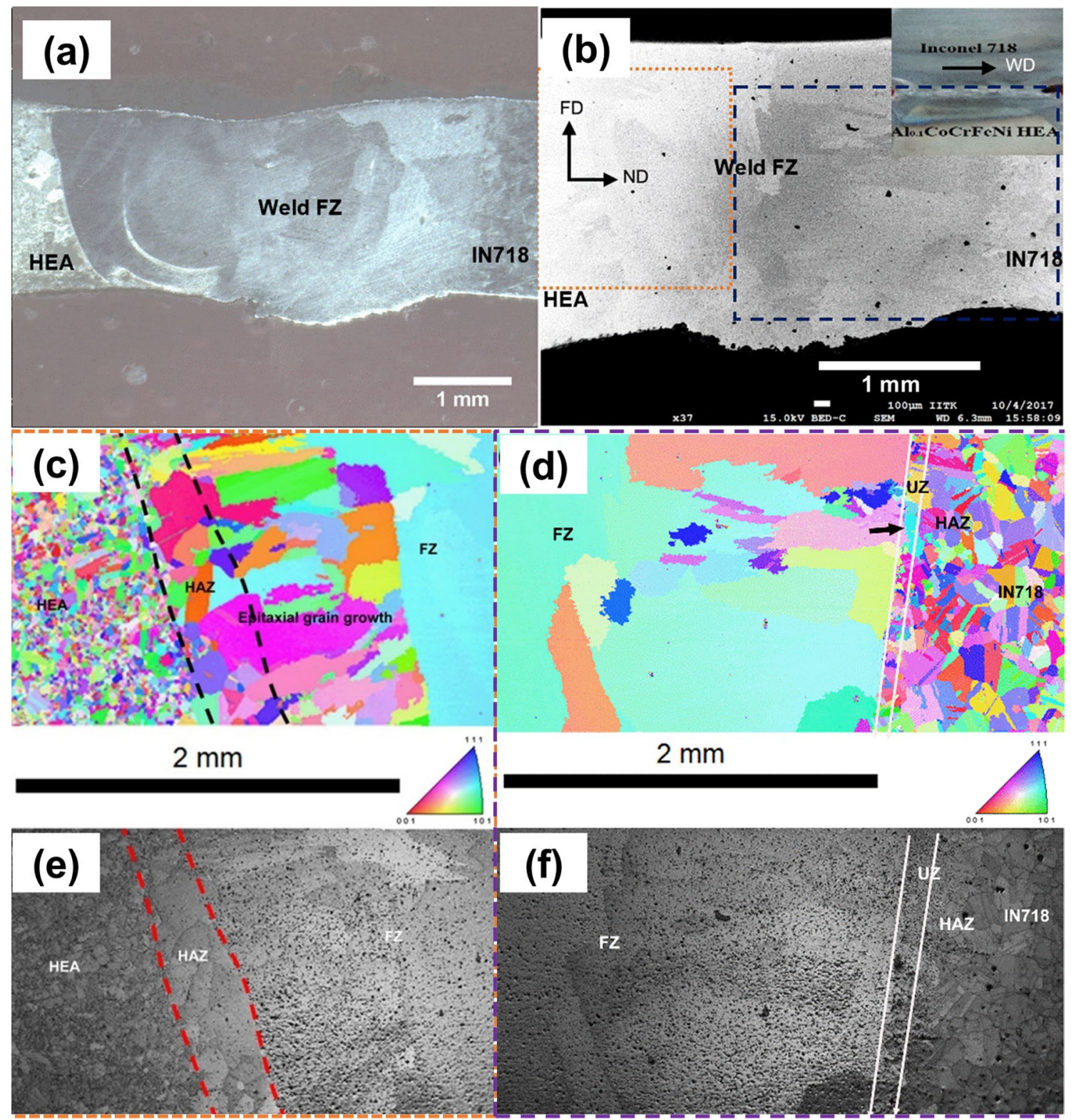

Figure 1: (a) and (b) Macroscopic view of the dissimilar weld joint under stereo microscope and scanning electron microscope (BSE mode) showing base metals and weld fusion zone with distinct fusion line at interfaces and inset of (b) shows bottom view of fabricated dissimilar weld showing full penetration; (c) and (d) Inverse pole figure (IPF) and (e) and (f) image quality maps of OIM of areas marked in 1 (b) comprising the HEA-BM, HHAZ and weld fusion zone and IN718-BM, IHAZ, UZ and weld fusion zone.

size distribution along the different regions of weldment evaluated from the EBSD data by the intercept method by excluding annealing twins is given in Fig. 3. Further, the high magnification images at the different zones of the weldments are shown in Fig. 4. The EDS spot analysis corresponding to the matrix, secondary phase, and precipitates in the weld fusion zone (FZ) and the EDS line analysis across the fusion lines were analyzed, and the results are presented in Fig. 5 and Tables 1 and 2. The statistical data, such as misorientation angles and Coincidence Site
Lattice (CSL) boundary fractions at different regions extracted from the EBSD data, are given in Fig. 6.

\section{Phase analysis}

The XRD patterns of the base metals (HEA and IN718) and the dissimilar weld are presented in Fig. 2. The presence of a single-phase FCC crystal structure is observed for the HEA. The 


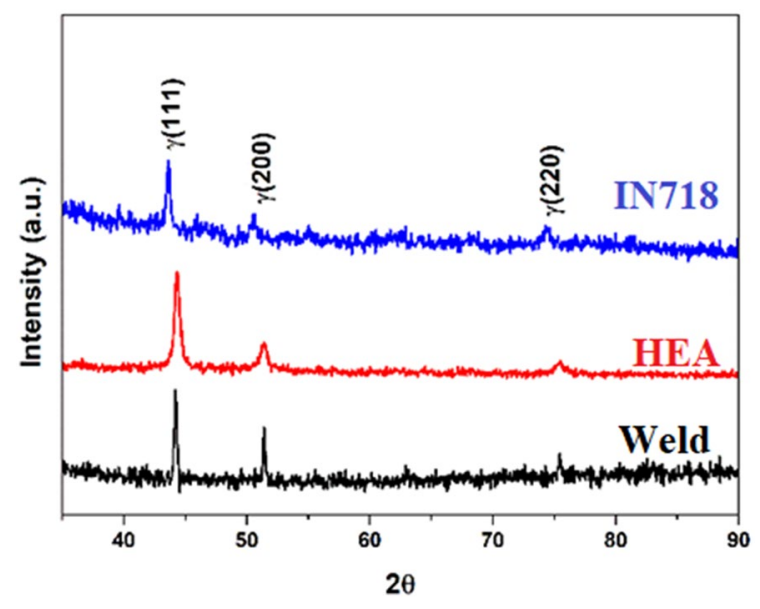

Figure 2: XRD patterns for base metals (HEA and IN718) and dissimilar weld.

XRD peaks corresponding to only $\gamma$-FCC austenitic phase could be noticed in IN718 and the absence of $\delta$-phase peaks could be the effect of heat treatment. From the XRD pattern, it can be observed that the weldment also shows the presence of the single-phase FCC crystal structure. No other phases (like the intermetallic phases) were present in the solidified weld metal. However, the microstructural analysis of the weld showed the presence of the $\mathrm{NbC}$ and the $\mathrm{Nb}$-rich Laves phases (will be discussed in the upcoming section) indicating that the fraction of these phases is very less to be detected by the X-ray diffractometer. The crystal size of BMs (HEA and IN718) and weldment were estimated to be $13.8 \mathrm{~nm}, 18.6 \mathrm{~nm}$, and $39 \mathrm{~nm}$, respectively, by using Williamson-Hall analysis [33].

\section{Microstructural analysis}

\section{Base metal}

The microstructures of the base metals viz, HEA, and IN718 presented in Fig. 1c and d show typical equiaxed austenitic grains with annealing twins. Such annealing twins form in the FCC alloys with low stacking fault energy during the recrystallization process [17]. It can be seen from Fig. 3 that the HEA and IN718 have an average grain size of about $\sim 27 \mu \mathrm{m}$ and $\sim 95 \mu \mathrm{m}$, respectively.

\section{Weld interfaces}

The interfaces between the HEA and the weld metal (IF-1), and the weld metal and IN718 (IF-2) are shown in Figs. 1c-f and $4 \mathrm{a}, \mathrm{b}$. It is evident from Figs. 1c, e and $4 \mathrm{a}$ that the columnar grains grow epitaxially from the partially melted grains in the BM (along the side of HEA) at IF-1. The epitaxial growth in the weld metal during welding is possible in dissimilar welding when the BM and the weld have a similar chemical composition and the same crystal structure [26]. The epitaxial growth ensures strong metallurgical bonding at the IF-1[28]. However, at IF-2, non-epitaxial growth of grains has been observed along with $0.15 \mathrm{~mm}$ thick fine-grained unmixed zone (UZ), which is shown in Figs. 1d, f and 4b. It is obvious from Fig. $1 \mathrm{~d}$ that the UZ region has a Type II grain boundary (as indicated by an arrow)
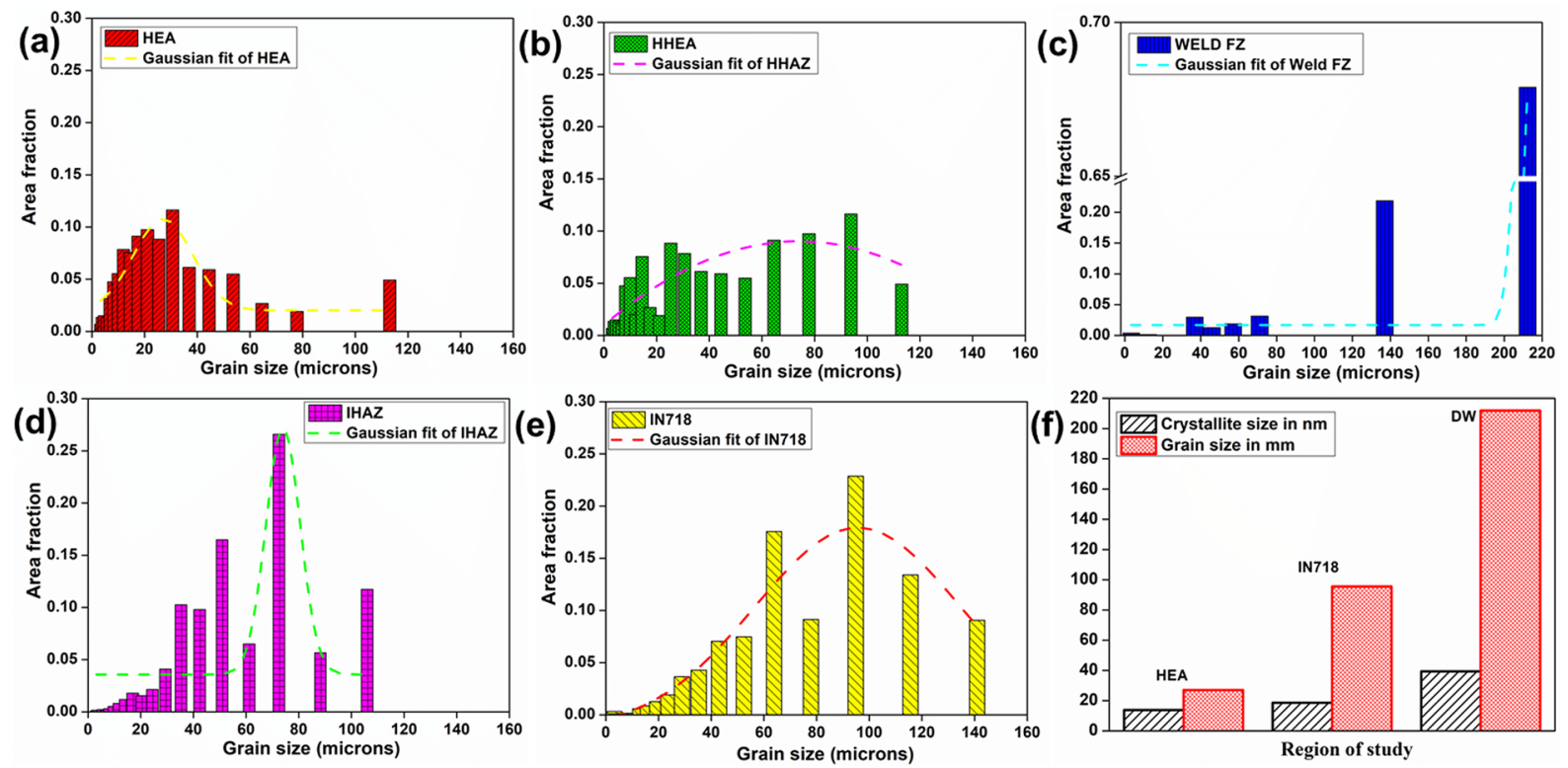

Figure 3: Grain size distribution in BMs (HEA (a) and IN718 (e)), corresponding HAZs (HHAZ (b) and IHAZ (d) and weld FZ (c) and variation of crystal size and average grain size in BMs and weld (f). 

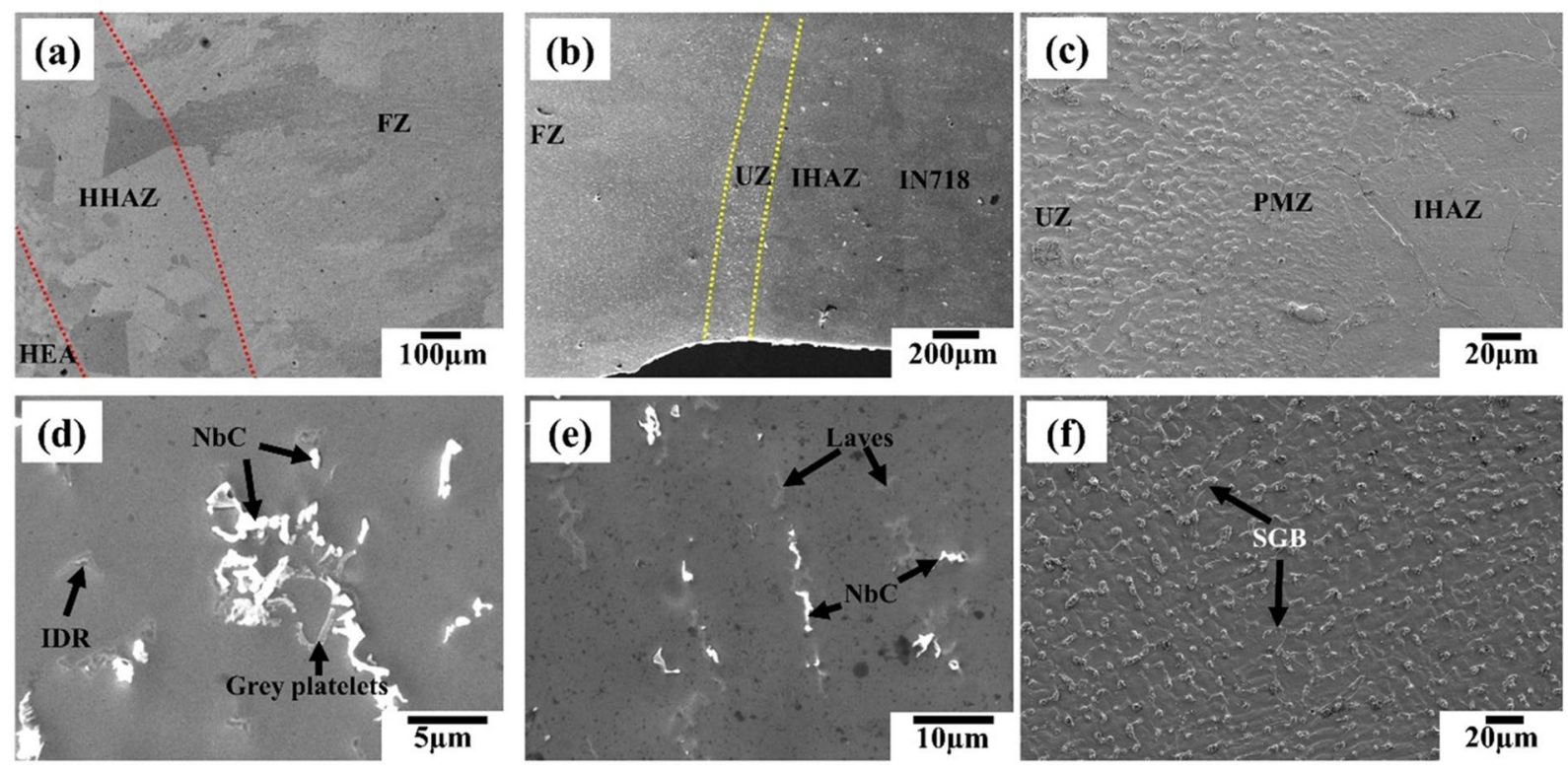

Figure 4: SEM micrographs of (a) IF-1 interface, (b) and (c) IF-2 interface in lower and higher magnification, (d) unmixed zone (UZ) and (e) and (f) weld fusion zone in lower and higher magnification.

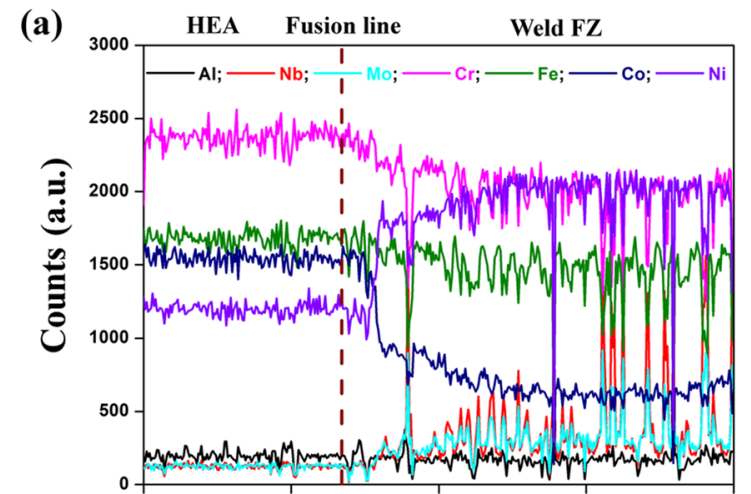

Distance $(\mu \mathrm{m})$

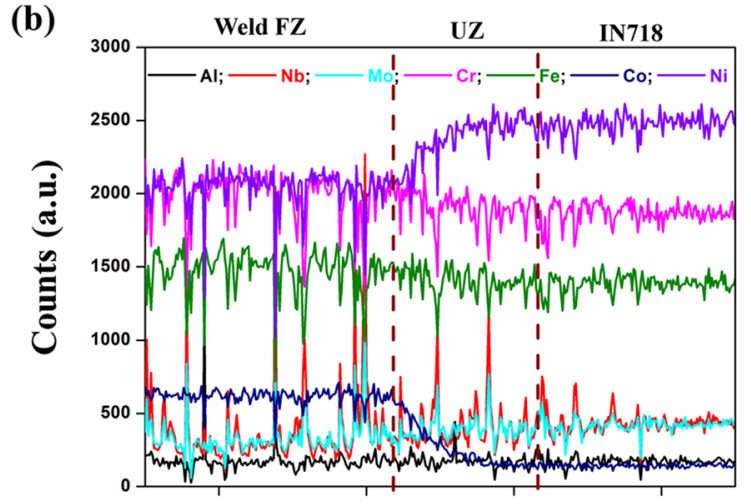

Distance $(\mu \mathrm{m})$

Figure 5: EDS line analysis of (a) IF-1 and (b) IF-2 interfaces.

TABLE 1: Chemical composition (wt $\%)$ of HEA, IN718, weld and UZ of dissimilar weld.

\begin{tabular}{lcccccccc}
\hline \hline $\begin{array}{l}\text { Region under } \\
\text { study }\end{array}$ & $\mathrm{Al}$ & $\mathrm{Si}$ & $\mathrm{Cr}$ & $\mathrm{Fe}$ & $\mathrm{Co}$ & $\mathrm{Ni}$ & $\mathrm{Nb}$ & $\mathrm{Mo}$ \\
\hline HEA & 0.89 & - & 23.48 & 25.05 & 25.56 & 23.28 & - & - \\
Weld & 1.78 & 0.47 & 22.54 & 21.70 & 9.65 & 40.15 & 2.41 & 1.26 \\
UZ & 0.85 & 0.18 & 19.85 & 20.01 & 5.19 & 45.65 & 5.47 & 2.78 \\
IN718 & 0.57 & 0.061 & 19.84 & 19.95 & 0.26 & 50.89 & 5.59 & 2.5 \\
\hline \hline
\end{tabular}

and Type I boundary. Type II boundary is discontinuous and runs parallel to the interface. However, Type I boundary runs perpendicular to the interface from the partially melted grains in the BM (along the IN718 side). Zhou et al. have reported that the UZs are more susceptible to cracking as well as corrosion than the BMs and the weld [34]. Besides, the presence of Type I and Type II high-angle grain boundaries makes these regions more susceptible to stress corrosion cracking [35]. Adjacent to UZ, the presence of the partially melted zone (PMZ) can be noticed, as shown in Fig. 4c. PMZ could form by the grain 
TABLE 2: Chemical composition of distinct features in unmixed zone (UZ) and weld fusion zone (FZ).

\begin{tabular}{llllllllr}
\hline \hline $\begin{array}{l}\text { Region } \\
\text { under study }\end{array}$ & Features & $\mathrm{Cr}$ & $\mathrm{Fe}$ & $\mathrm{Co}$ & $\mathrm{Ni}$ & $\mathrm{Nb}$ & $\mathrm{Mo}$ & $\mathrm{C}$ \\
\hline UZ & NbC & 4.2 & 3.6 & - & 7.5 & 61.7 & - & 23.0 \\
& Grayish platelets & 19.3 & 18.7 & - & 48.3 & 7.4 & - & 6.3 \\
& Interdendrites (IDR) & 13.8 & 14.3 & - & 45.0 & 17.3 & - & 9.5 \\
& Matrix & 16.8 & 16.4 & - & 44.9 & 3.8 & 2.4 & 15.7 \\
& NbC & 10.5 & 5.7 & - & 23.3 & 43.2 & - & 17.1 \\
& Interdendrites (IDR)/Laves & 12.9 & 13.9 & 10.1 & 34.3 & 23.3 & - & 5.5 \\
& Matrix & 20.6 & 22.8 & 9.9 & 42.4 & - & - & 4.4 \\
\hline \hline
\end{tabular}
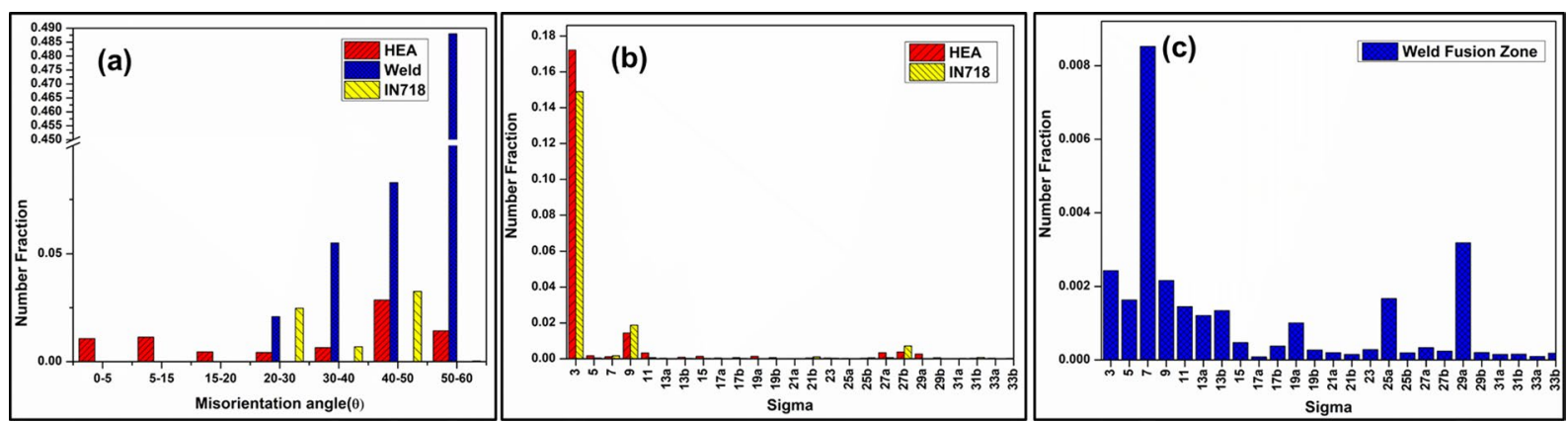

Figure 6: (a) Misorientation angle distribution in BMs (HEA and IN718) and weld FZ and (b) and (c) CSL boundary distribution in BMs (HEA and IN718) and weld FZ respectively.

boundary wetting as a consequence of constitutional liquation. Also, PMZ is susceptible to liquation cracking, which can act as a crack initiator under load and deteriorate the ductility of the weldment [26].

In the magnified image of UZ. (Fig. 4d), dispersion of a colony of white precipitates, grayish platelets, and dendritic phases in the matrix are apparent. The elemental compositions obtained from the EDS analysis conducted on these precipitates/phases are given in Table 2. It confirms that the white precipitates correspond to $\mathrm{NbC}$ phase, and the grayish platelets and interdendritic (IDR) phases correspond to the Nb-rich eutectic Laves phase. Such occurrence of Laves is very common in the welds of IN718 [36]. Knorovsky et al. have found that the solidification path in IN718 superalloy is initiated with the formation of Chinese script like $\gamma / \mathrm{NbC}$ phase and ended with $\gamma /$ Laves eutectic reactions [37]. It is inferred from Fig. $4 \mathrm{~d}$ that the grayish platelets (Nb-rich Laves phase) would have formed underneath the $\mathrm{NbC}$ precipitates during solidification. Also, in the IDR region, the Laves phases have formed around the $\mathrm{NbC}$ precipitate. Hence, the colonies of $\mathrm{NbC}$ precipitates and Laves formation at $\mathrm{UZ}$ follow the $\mathrm{L} \rightarrow \gamma / \mathrm{NbC}+\mathrm{L}$ and subsequent $\mathrm{L} \rightarrow \gamma+$ Laves eutectic reactions and is in line with the IN718 alloy solidification concept proposed by Knorovsky et al. [37]. Though, the fraction of austenite stabilizing $\mathrm{Ni}$ is more in the weld metal, a marginal increase in the concentration of other elements (such as Fe and $\mathrm{Cr}$ ) promotes the Laves phase formation. The formation of $\mathrm{NbC}$ and Laves phase is due to the partial solubility of $\mathrm{Nb}$ and $\mathrm{Mo}$ in the $\gamma$-austenitic matrix. Besides, the diffusion of $\mathrm{Nb}$ into the matrix after solidification is limited by its lower diffusivity [23]. Generally, the interstitial carbon has higher diffusivity compared to the other substitutional alloying elements and exhibits a tendency to migrate from the region of higher $\mathrm{Cr}$ concentration to the region of lower concentration [24]. The EDS results in Table 1 show that the concentration of $\mathrm{Cr}$ decreases from HEA to IN718 across the weld. Carbon atoms in the molten weld pool migrate from the weld metal with a high $\mathrm{Cr}$ concentration toward IN718. Hence, the migration of $\mathrm{C}$ from $\mathrm{Cr}$-rich weld metal to Cr-deficient IN718-BM leads to the formation of colonies of NbC precipitates in the UZ.

The $\mathrm{NbC}$ and Laves phase at the UZ provides the sites for heterogeneous nucleation and increase the constitutional supercooling for further growth of the dendritic columnar grains. As $\mathrm{UZ}$ is formed by the phenomenon of direct re-melting and solidification of the BM without any dilution, it is expected to possess a similar composition of BM [34]. The EDS line maps of the five elements of HEA along with $\mathrm{Nb}$ and Mo from IN718, whose segregation decides the structure of the weldment, are given in Fig. 5. The line mapping from IN718 to UZ shows significant variations in the elemental distribution of $\mathrm{Nb}$ and $\mathrm{Mo}$, while the other elements are nearly equally distributed. It indicates that the matrix in the UZ has a composition similar to IN718$\mathrm{BM}$, while the sudden hike in $\mathrm{Nb}$ and Mo denotes the presence 
of $\mathrm{NbC}$ and Laves phase in this region. The EDS analysis of the weld metal (Table 1) suggests that the weld is virtually similar in the composition of HEA, while the composition of IN718 does not match that of the weld metal. Since the weld metal and BM have the same crystal structure, and similar chemical composition [26], the IF-1 shows the presence of epitaxial growth. On the other hand, though BM (IN718) and weld are of the same crystal structure in IF-2, the apparent chemical inequality restricts the epitaxial growth with the formation of narrow $\mathrm{UZ}$.

\section{Weld fusion zone}

The grains in the FZ that grow from the weld interfaces are coarser than that of the BMs and respective HAZs (Figs. 1c- $\mathrm{f}$ and 3). The coarsening of the grain in FZ follows the same trend as the crystal size evaluated from the XRD pattern (Fig. 3f). However, the extent of coarsening is more pronounced on the IF-2 side than the IF-1 side. This predominant coarsening of columnar grains adjacent to the IF-2 interface could be attributed to the extensive lateral growth of the dendritic substructures in favorably oriented grains in non-epitaxial mode than the grains with epitaxial growth. The columnar grain growth along the weld direction from these interfaces is the result of the steep temperature gradient that exists along the weld direction as the welding torch shifts its position continuously. These columnar grains are reported to form through competitive growth mechanisms as dendrites [38]. Unlike in the BM, the welding results in coarser and elongated grains in the weld metal. Such grain coarsening in $\mathrm{FZ}$ is a common phenomenon in the welding of materials [26] and could deteriorate the mechanical property of the weld joint. The average grain size at the FZ center is observed to be around $100 \mu \mathrm{m}$. It is a well-known phenomenon that the grain growth in FZ during solidification of the weld pool always follows the easy growth direction, i.e., $<001>$ direction for FCC and BCC structured alloys [26]. However, EBSDOrientation Imaging Microscopy (OIM) images show that the grain orientation deviates from $<001>$ direction to random grain orientations, which is similar to the observations made by Wu et al. [16].

The magnified image (Fig. 4e) of the columnar grain in the $\mathrm{FZ}$ reveals the dendritic substructures with the segregation of $\mathrm{NbC}$ and $\mathrm{Nb}$-rich Laves phase along IDR in the matrix. The EDS spot analysis at these phases is given in Table 2. Such secondary phase segregation in FZ is attributed to the lower solubility and slow diffusion kinetics of $\mathrm{Nb}$ in the austenitic matrix. It is evident from Fig. $4 \mathrm{~d}$ and e that the fraction of $\mathrm{NbC}$ precipitates at the weld center are less and discrete. Since the weld center is the last region to solidify in the weld, the formation of $\mathrm{NbC}$ in $\mathrm{UZ}$ and $\mathrm{FZ}$ at the vicinity of $\mathrm{UZ}$ depletes the $\mathrm{Nb}$ and $\mathrm{C}$ content in the remaining weld pool. Hence, the consumption of a significant amount of $\mathrm{Nb}$ and $\mathrm{C}$ at $\mathrm{UZ}$ for $\mathrm{NbC}$ and Laves formation reduces the fraction of $\mathrm{NbC}$ in the weld center. Though the Laves phase in the weld and UZ has a nearly similar chemical composition, the Laves phase in the UZ is formed from the terminal solution without Co content. This indicates that the Co from HEA has not diffused to the UZ. The fusion zone etched with $10 \%$ oxalic acid at high magnification reveals the presence of solidification grain boundary (SGB) formed by the intersection of the group of dendritic substructures (Fig. 4f). The higher probability of solute segregation at the SGB makes the weld vulnerable to solidification cracking. Even though some studies suggest that the NbC dispersion in weld metal improves creep resistance at high-temperature [39], the segregation of precipitation strengthening elements $(\mathrm{Nb}, \mathrm{Al}$, and $\mathrm{Ti}$ ) [40] toward IDR could weaken the matrix and reduce the strength of both weld FZ and UZ. In addition, the presence of $\mathrm{NbC}$ and Laves phases could increase the possibility of hot cracking susceptibility and may reduce the ductility of the weld [39]. Hence, grain coarsening coupled with segregation could deteriorate the mechanical properties as a consequence of a reduction in grain boundary strengthening and an early crack initiation at pores, $\mathrm{NbC}$, and the brittle Laves phases during plastic deformation.

\section{Heat affected zone}

By close analysis of Figs. 1c-f and $4 \mathrm{a}, \mathrm{b}$, it is obvious that the HAZ along the HEA side (HHAZ) has experienced a significant grain growth with the presence of a substantial amount of twins. However, the HAZ is associated with the PMZ along the IN718 side (IHAZ) evidenced no such grain coarsening. However, the grain boundary liquation is apparent in the PMZ (Fig. 4c). Owing to the heavy lattice distortion and sluggish cooperative diffusion in the HEA, it shows poor thermal conductivity compared to the IN718. The HAZ in the material with lower thermal conductivity would dwell at a higher temperature for a longer duration compared to the HAZ of the material with higher conductivity [31]. The prolonged exposure of the grains above its recrystallization temperature could assist grain growth by the static partial recrystallization phenomenon. At the same time, in a material with a single-phase in the absence of secondary phases, there is no restriction for such growth. The presence of annealing twins in HHAZ substantiates the occurrence of static partial recrystallization of grains during the heating cycle.

\section{Grain boundary distribution and misorientation}

Figure 6a shows the distribution of grain misorientation angle in various regions of the weldment, such as; BMs, HAZ, UZ, and FZ. Grain boundaries can be categorized as a low angle grain boundary (LAB), medium angle grain boundary (MAB), 
and high-angle grain boundary (HABs) based on the misorientation angle [31]. The grain boundaries with misorientation angle $(\theta)$ less than $5^{\circ}$, in-between $5^{\circ}$ and $15^{\circ}$ and, $15^{\circ}$ and $180^{\circ}$ are classified as LABs, MABs, and HABs, respectively. According to Palumbo-Aust's criterion $\left(\Delta \theta=15^{\circ} \Sigma 5 / 6\right)$ [41], HABs are further categorized as the coincident site lattice or special twin boundary $(3 \leq \Sigma \leq 29)$ and random high-angle grain boundaries (RGBs) [31]. The number fractions of primary twins $(\Sigma 3)$ and corresponding higher-order twins having $\Sigma 3 \mathrm{n}$ values, where $n>1$ for the BMs (HEA and IN718) and the weld are presented in the Fig. 6b, c.

Analyzing the misorientation distribution (Fig. 6a) and CSL grain boundary distribution (Fig. 6b, c) of FZ and BMs carefully, it can be concluded that the weld metal shows more fraction of RGBs due to as-cast microstructure [42], while both HEA and IN718 demonstrate special CSL twin boundary character. HEA base metal reveals a significant fraction of LABs (sub-grain boundaries) corroborates the static and dynamic recrystallization of the grains during hot forging (Fig. 6a). The occurrence of a certain amount of $\Sigma 9$ boundaries in the HEA and IN718 grains indicates the presence of the marginal amount of incoherent twins. However, FZ shows higher fraction of $\Sigma 5$ coincidence boundaries as a result of grain growth (Fig. 1c-f). Wang et al. have demonstrated that these $\Sigma 5$ coincidence boundaries are more mobile than other CSL boundaries [43]. Since more residual strain could be concentrated at the FZ during solidification as a consequence of weld shrinkage, the RGB fraction in the weld (as represented by Ma et al. [44]) is very high compared to the BMs. Higher boundary energy in RGBs catalyzes the segregation of solutes such as $\mathrm{NbC}$ and Laves. The evolution of continuous random boundary networks around coarse grains with a reduced fraction of CSL boundaries after welding may alter their mechanical properties [32].

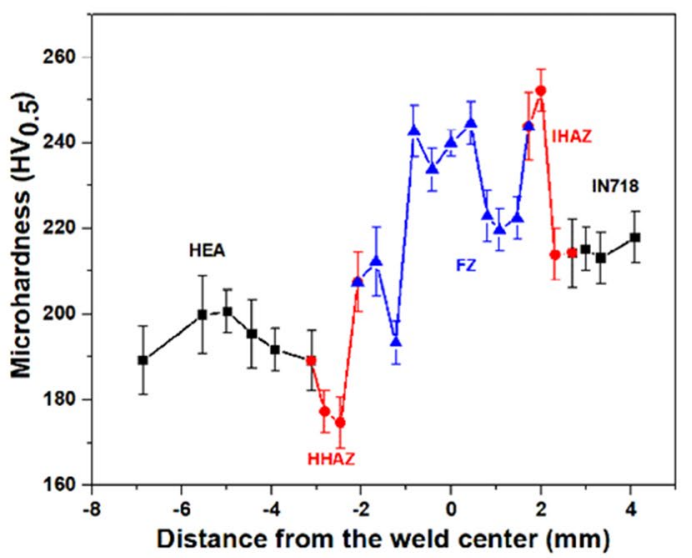

\section{Mechanical properties}

The microhardness survey across the weld presented in Fig. 7a shows that the hardness of FZ is higher than that of the HEA and marginally lower than that of IN718. A sudden hardness drop is observed at the HHAZ and is attributed to the coarse grain structure. Mortezaie and Shamanian have also found such a reduction in the hardness values in the coarse HAZ of austenitic stainless steel when welded to nickel-base alloys [23]. However, the hardness at IHAZ is higher than that of the base metals. The noticed higher hardness values of IHAZ are due to the presence of the NbC precipitates, as shown in Fig. 5. The transverse tensile test results of BMs and the weldment are presented in Fig. 7b. Yield strength (YS) and ultimate tensile strength (UTS) of IN718 are observed to be $647 \mathrm{MPa}$ and $1350 \mathrm{MPa}$, respectively, with the ductility of $89 \%$, while the same of HEA is $502 \mathrm{MPa}$ and $735 \mathrm{MPa}$, respectively with the ductility of $37 \%$. The strength of the HEA is higher than the strength of the earlier reported HEAs in the homogenized condition [17]. This could be attributed to the Hall-Petch strengthening in the present HEA, where the grain refinement is observed compared to the homogenized counterpart, as reported by Wu et al. [45]. However, the tensile strength of the weldment is lower than that of HEA and IN718. The tensile sample of the dissimilar weld failed at the weld center (inset in Fig. 7b). The YS and UTS of the dissimilar weld joint are $443 \mathrm{MPa}$ and $644 \mathrm{MPa}$, respectively, with a ductility of $21 \%$. The reduction in the strength of the dissimilar $\mathrm{Al}_{0.1} \mathrm{CoCrFeNi}-\mathrm{HEA} /$ IN718 weld joint is attributed to the coarse-grained structure at the FZ compared to the BMs. Further, the possible earlier crack initiation at pores, SGBs and, brittle NbC and Laves phases in the coarse weld metal grains could have caused the fracture in the weld, associated with a reduction in ductility [41].

The fractography images of the fractured tensile samples of the BMs and the weld are presented in Fig. $8 \mathrm{a}-\mathrm{c}$ respectively. The HEA sample failed in a transgranular mode; the fracture

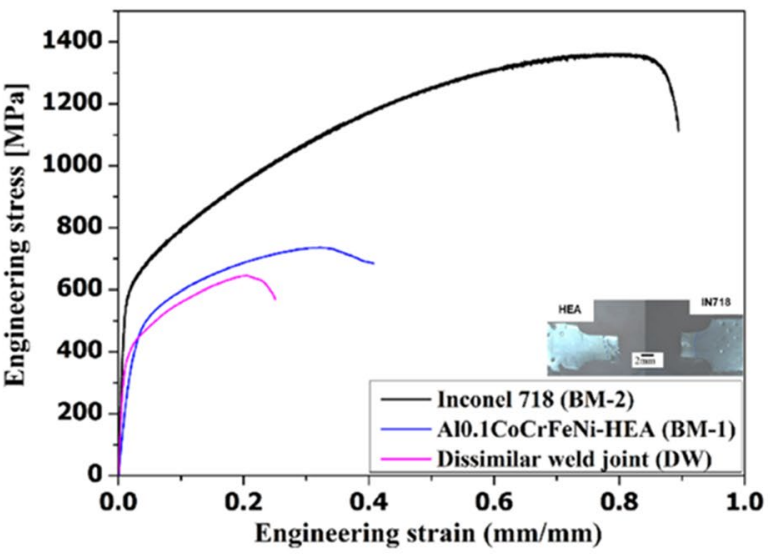

Figure 7: (a) Microhardness Survey across the dissimilar weld joint. (b) Engineering stress-strain curves for BMs (HEA and IN718) and dissimilar weld joint with macroscopic picture of fractured sample showing the fracture occurrence at the weld and (c). 


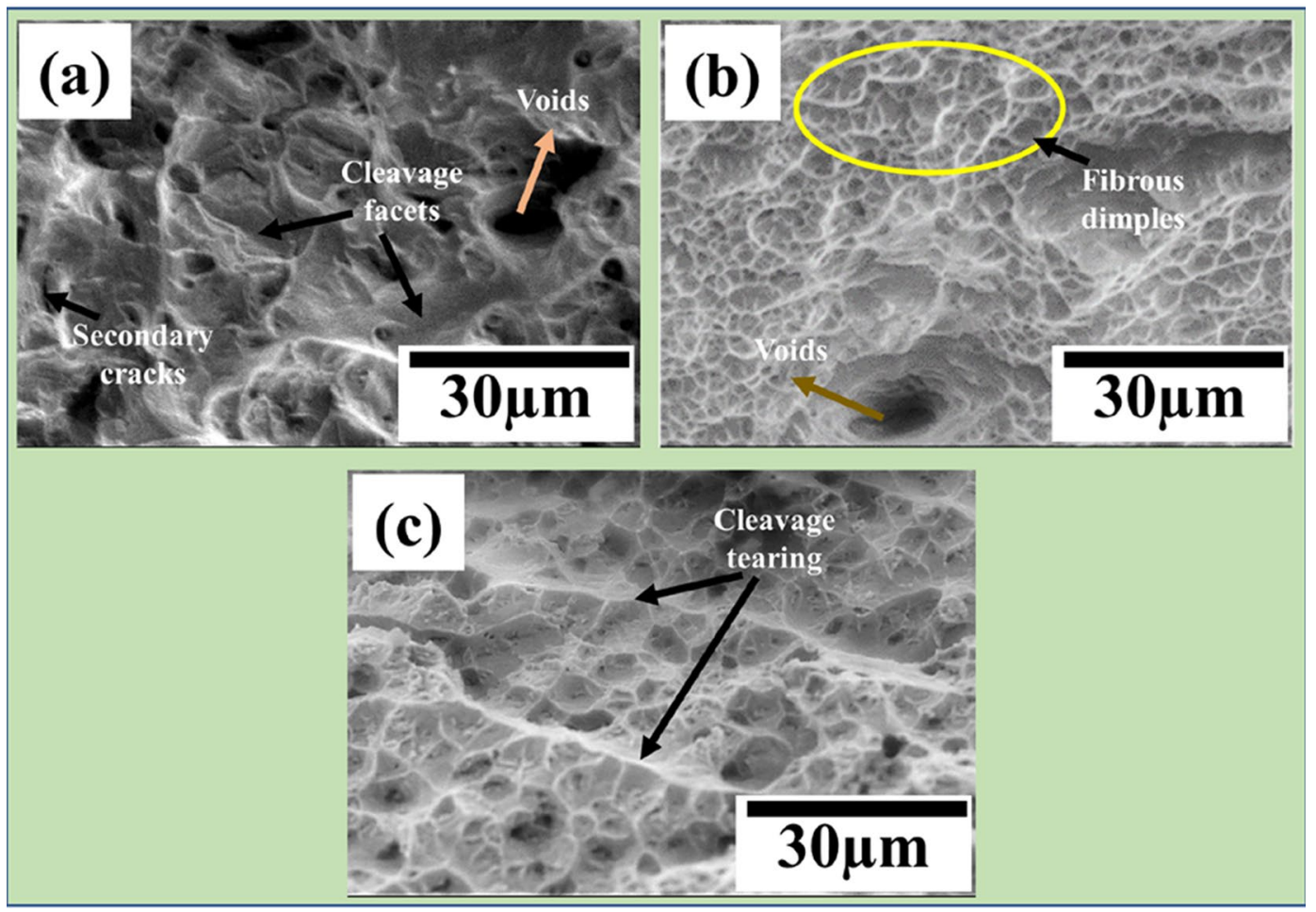

Figure 8: SEM fractographs of tensile fracture surfaces of base metals (a) HEA and (b) IN718 and dissimilar weld joint.

surface also exhibits deeper elongated dimples along the grain boundaries. In addition, along with the micro and macro voids, both secondary cracking and smooth surface are observed due to cleavage fracture. Such secondary cracking and smooth cleavage in the fracture surface could adversely affect the ductility by rapid crack initiation and propagation [46]. However, in the case of IN718, the fracture surface reveals the fine fibrous dimples due to micro void growth, indicating that IN718 has experienced significant plastic deformation before failure [47]. A quasi-cleavage fracture with river line markings in addition to dimples structure is noticed in the fracture surface of the weld metal. The quasi-cleavage mode of fracture in the weld metal is due to the presence of hard secondary phases like $\mathrm{NbC}$ and Laves phases along the SGBs and interdendrites in the coarse columnar grains. This secondary phase could initiate the crack leading to crack propagation and causing a reduction of ductility in the weld metal.

Finally, the weld efficiency of the dissimilar weld joint was calculated as $\sim 88 \%$ by comparing the strength of the weld $\left(\sigma_{w}\right)$ to the BM with a lower strength $\left(\sigma_{L}\right)$ as a reference, where, the dissimilar weld joint efficiency, $\left.\eta=\left(\sigma_{w}\right) / \sigma_{L}\right)^{\star} 100 \%$. Comparing the weld joint strength with the recent works on similar [16] and GTAW of HEA and HEA/stainless steel joints [27, 28], the present joint shows better strength than the similar CoCrFeMnNiHEA and dissimilar $\mathrm{Al}_{0.1} \mathrm{CoCrFeNi-HEA/AISI304} \mathrm{stainless} \mathrm{steel}$ welds produced with GTAW. The results prove the possibility of fabricating dissimilar $\mathrm{Al}_{0.1} \mathrm{CoCrFeNi}$-HEA/IN718 weld joint by the gas tungsten arc welding process. However, the fracture at the weld zone is not recommended if the structural part is designed by considering the properties of base metal with a lower strength (say HEA). Hence, the following techniques are recommended to improve the weld joint strength; (i) by using appropriate filler metals [23-25], (ii) grain refinement in the weld metal by electromagnetic arc oscillation [36], or (iii) by selecting suitable welding processes that can produce narrow weld bead [26].

\section{Conclusions}

The results of the present study lead to the following outcomes:

- The $\mathrm{Al}_{0.1} \mathrm{CoCrFeNi}$ - HEA is amenable for dissimilar welding with IN718 by GTA welding, and a sound dissimilar weld joint can be produced.

- In GTA welding of $\mathrm{Al}_{0.1} \mathrm{CoCrFeNi}-\mathrm{HEA}$ to IN718, the epitaxial growth of columnar dendritic grains occurs at the HEA-weld interface as the chemical composition of the weld is close to $\mathrm{Al}_{0.1} \mathrm{CoCrFeNi}-\mathrm{HEA}$ composition. However, unmixed zones with a dispersion of large fractions of $\mathrm{NbC}$ 
followed by columnar dendritic coarse grain, are observed along with the IN718 weld interface. Also, the weld center reveals the presence of discrete $\mathrm{NbC} /$ Laves phases.

- The presence of a high fraction of random high-angle boundary (RGBs) with high grain boundary energy encourages the segregation of the $\mathrm{NbC/Laves} \mathrm{phases.} \mathrm{Further,} \mathrm{the}$ higher concentration of residual strains along RGBs promotes early crack initiation.

- The dissimilar joint weld efficiency is calculated as $~ 88 \%$ in comparison with HEA base metal. YS and UTS of the weldment are $443 \mathrm{MPa}$ and $644 \mathrm{MPa}$, respectively. Fracture occurrence at the weld fusion zone is attributed to the coarse grains and the presence of the hard phases like $\mathrm{NbC}$ and laves along with SGBs in the weld fusion zone. The weld metal has exhibited a mixed ductile and brittle fracture mode with reduced ductility.

\section{Materials and methods}

$\mathrm{Al}_{0.1} \mathrm{CoCrFeNi}$-HEA and IN718 alloys with a thickness of $2 \mathrm{~mm}$ were considered as the base metals (BM) for the present study. $\mathrm{Al}_{0.1} \mathrm{CoCrFeNi-HEA}$ was fabricated through a vacuum arc melting technique, as mentioned in earlier studies [18-20]. Elements ( $\mathrm{Al}, \mathrm{Co}, \mathrm{Cr}, \mathrm{Fe}$, and $\mathrm{Ni}$ ) in the form of pellets, having a purity higher than $99.5 \%$, were used for alloy preparation. The alloy thus obtained was re-melted at least 4-5 times to ensure compositional homogeneity. The resultant button type sample ( $\sim 7 \mathrm{~mm}$ thick) was homogenized (at $1050{ }^{\circ} \mathrm{C}$ for $60 \mathrm{~h}$ with subsequent furnace cooling) $[18,19]$ and drop forged (at $\sim 700^{\circ} \mathrm{C}$ ) to a thickness of $2.5 \mathrm{~mm}$ followed by surface grinding to reduce the thickness to $2 \mathrm{~mm}$. Finally, the $2 \mathrm{~mm}$ thick $\mathrm{Al}_{0.1} \mathrm{CoCrFeNi}$-HEA was annealed (at $1050{ }^{\circ} \mathrm{C}$ for $2 \mathrm{~h}$ with subsequent furnace cooling) and was used as one of the base materials. A coupon of dimension $25 \mathrm{~mm} \times 250 \mathrm{~mm} \times 2 \mathrm{~mm}$ was extracted using wire-EDM cutting from the as-received IN718 alloy and was heat-treated at $900{ }^{\circ} \mathrm{C}$ for one hour and subsequently cooled in the atmospheric air. The test coupons were mechanically polished before welding.

An autogenous dissimilar butt welding between HEA and IN718 was carried out with a mechanized GTA weld setup. The welding was performed with the welding parameters; voltage, current, and heat input of $10 \mathrm{~V}, 50 \mathrm{~A}$, and $180 \mathrm{~J} / \mathrm{mm}$, respectively, at a traverse speed of $100 \mathrm{~mm} / \mathrm{min}$. The microstructure of the weld joint was observed under a stereomicroscope and a scanning electron microscope (SEM). X-ray diffractograms were obtained from the Ultima III, Rigaku, X-ray diffractometer with $\mathrm{Cu}-\mathrm{Ka}$ radiation at an operating voltage of $40 \mathrm{kV}$ and a current of $30 \mathrm{~mA}$. The scans were ranging between $20^{\circ}$ to $90^{\circ}$, and the measurements were carried out in steps of $0.05^{\circ}$. The micro-texture of the transverse section of the weldment was studied by using Electron Backscatter Diffraction (EBSD). The reference coordinates used for the scanning are fixed as normal direction (ND), weld metal filling direction/thickness direction (FD), and welding directions (WD), as mentioned in Fig. 1. Energy-dispersive X-ray spectroscopy (EDS) was employed to study the elemental distribution across the weldment. Microhardness survey on the surface perpendicular to the welding direction on the surface of the weld was performed under an applied load of $500 \mathrm{~g}$. Tensile tests on the BMs and the dissimilar weld joints were conducted at a strain rate of $10^{-2} / \mathrm{s}$ on micro tensile samples extracted with the dimensions given in the schematic diagram shown in Fig. S1 (Supplementary Figure).

\section{Acknowledgments}

The authors would like to thank Professor Indradev Samajdar, Department of Metallurgical Engineering and Materials Science, IIT-Bombay, India, for providing electron backscattered diffraction (EBSD).

\section{Funding}

Funding from the SPARC program (Government of India) and European Regional Development Grant (Grant No: ASTRA6-6) are greatly acknowledged.

\section{Data availability}

The datasets generated during and/or analyzed during the current study are available from the corresponding author(s) on reasonable request.

\section{Declarations}

Conflict of interest The authors have no conflicts of interest to disclose the data.

\section{Open Access}

This article is licensed under a Creative Commons Attribution 4.0 International License, which permits use, sharing, adaptation, distribution and reproduction in any medium or format, as long as you give appropriate credit to the original author(s) and the source, provide a link to the Creative Commons licence, and indicate if changes were made. The images or other third party material in this article are included in the article's Creative Commons licence, unless indicated otherwise in a credit line to the material. If material is not included in the article's Creative Commons licence and your intended use is not permitted by statutory regulation or exceeds the permitted use, you will need to obtain permission directly from the copyright holder. 
To view a copy of this licence, visit http://creativecommons.org/ licenses/by/4.0/.

\section{Supplementary Information}

The online version contains supplementary material available at https://doi.org/10.1557/s43578-021-00352-w.

\section{References}

1. J.W. Yeh, S.K. Chen, S.J. Lin, J.Y. Gan, T.S. Chin, T.T. Shun, C.H. Tsau, S.Y. Chang, Nanostructured high-entropy alloys with multiple principal elements: novel alloy design concepts and outcomes. Adv. Eng. Mater. 6, 299 (2004)

2. B. Cantor, I.T.H. Chang, P. Knight, A.J.B. Vincent, Microstructural development in equiatomic multicomponent alloys. Mater. Sci. Eng. A. 375-377, 213 (2004)

3. B.S. Murty, J.W. Yeh, S. Ranganathan, High-Entropy Alloys, 1st edn. (Elsevier, London, 2014)

4. Z. Fu, B.E. MacDonald, A.D. Dupuy, X. Wang, T.C. Monson, R.E. Delaney, C.J. Pearce, K. Hu, Z. Jiang, Y. Zhou, J.M. Schoenung, W. Chen, E.J. Lavernia, Exceptional combination of soft magnetic and mechanical properties in a heterostructured highentropy composite. Appl. Mater. Today. 15, 590 (2019)

5. Y. Zhang, T. Zuo, Z. Tang, M.C. Gao, K.A. Dahmen, P.K. Liaw, Z.P. Lu, Microstructures and properties of high-entropy alloys. Progr. Mater. Sci. 61, 1 (2014)

6. K. Liu, S.S. Nene, M. Frank, S. Sinha, R.S. Mishra, Extremely high fatigue resistance in an ultrafine grained high entropy alloy. Appl. Mater. Today. 15, 525 (2019)

7. Y.F. Ye, Q. Wang, J. Lu, C.T. Liu, Y. Yang, High-entropy alloy: challenges and prospects. Mater. Today 19, 349 (2016)

8. W.R. Wang, W.L. Wang, S.C. Wang, Y.C. Tsai, C.H. Lai, J.W. Yeh, Effects of $\mathrm{Al}$ addition on the microstructure and mechanical property of AlxCoCrFeNi high-entropy alloys. Intermetallics 26, 44 (2012)

9. W.R. Wang, W.L. Wang, J.W. Yeh, Phases, microstructure and mechanical properties of AlxCoCrFeNi high-entropy alloys at elevated temperatures. J Alloy Compd. 589, 143 (2014)

10. D.Y. Li, Y. Zhang, The ultrahigh charpy impact toughness of forged $\mathrm{Al}_{\mathrm{x}} \mathrm{CoCrFeNi}$ high entropy alloys at room and cryogenic temperatures. Intermetallics 70, 24 (2016)

11. N. Kumar, Q. Ying, X. Nie, R.S. Mishra, Z. Tang, P.K. Liaw, R.E. Brennan, K.J. Doherty, K.C. Cho, High strain-rate compressive deformation behavior of the $\mathrm{Al}_{0.1} \mathrm{CrFeCoNi}$ high entropy alloy. Mater Des. 86, 598 (2015)

12. R. Sokkalingam, K. Sivaprasad, V. Muthupandi, Welding of high entropy alloys, in High entropy alloys:innovations, advances, and applications. ed. by T.S. Srivatsan, M. Gupta (CRC Press, Boca Raton, 2020), p. 598

13. F.C.G. Filho, S.N. Monteiro, Welding joints in high entropy alloys: a short-review on recent trends. Materials. 14, 1411 (2020)

14. J. Li, X. Meng, L. Wan, Y. Huang, Welding of high entropy alloys: progresses, challenges and perspectives. J. Manuf. Process. 68, $293(2021)$

15. M. Rhode, T. Richter, D. Schroepfer, A.M. Manzoni, M. Schneider, G. Laplanche, Welding of high-entropy alloys and compositionally complex alloys-an overview. Weld. World. 65, 1645 (2021)

16. Z. Wu, S.A. David, D.N. Leonard, Z. Feng, H. Bei, Microstructures and mechanical properties of a welded CoCrFeMnNi highentropy alloy. Sci Technol Weld Join. 23, 585 (2018)

17. M. Komarasamy, N. Kumar, Z. Tang, R.S. Mishra, P.K. Liaw, Effect of Microstructure on the deformation mechanism of friction stir-processed $\mathrm{Al}_{0.1} \mathrm{CoCrFeNi}$ high entropy alloy. Mater Res Lett. 3, 30 (2015)

18. R. Sokkalingam, S. Mishra, S.R. Cheethirala, V. Muthupandi, K. Sivaprasad, Enhanced relative slip distance in gas-tungsten-arcwelded $\mathrm{Al}_{0.5} \mathrm{CoCrFeNi}$ high-entropy alloy. Metall Mater Trans A. 48, 3630 (2017)

19. R. Sokkalingam, K. Sivaprasad, V. Muthupandi, M. Duraiselvam, Characterization of laser beam welded $\mathrm{Al}_{0.5} \mathrm{CoCrFeNi}$ highentropy alloy. Key Eng Mater. 775, 448 (2018)

20. R. Sokkalingam, K. Sivaprasad, V. Muthupandi, M. Duraiselvam, K.G. Prashanth, Novel welding of $\mathrm{Al}_{0.5} \mathrm{CoCrFeNi}$ high-entropy alloy: corrosion behavior. J Alloy Compd. 817, 153163 (2020)

21. M. Nahmany, Z. Hooper, A. Stern, V. Geanta, I. Voiculescu, AlxCrFeCoNi high-entropy alloys: surface modification by electron beam bead-on-plate melting. Metallogr Microstruct Anal 5, 229 (2016)

22. L. Cui, B. Ma, S.Q. Feng, X.L. Wang, Microstructure and mechanical properties of high-entropy alloys CoCrFeNiAl by welding. Adv Mater Res. 936, 1635 (2014)

23. A. Mortezaie, M. Shamanian, An assessment of microstructure, mechanical properties and corrosion resistance of dissimilar welds between Inconel 718 and 310 S austenitic stainless steel. Int J Pres Ves Pip. 116, 37 (2014)

24. R. Nivas, P.K. Singh, G. Das, S.K. Das, S. Kumar, B. Mahato, K. Sivaprasad, M. Ghosh, A comparative study on microstructure and mechanical properties near interface for dissimilar materials during conventional V-groove and narrow gap welding. J Manuf. Process. 25, 274 (2017)

25. T. Ramkumar, M. Selvakumar, P. Narayanasamy, A.A. Begam, P. Mathavan, A.A. Raj, Studies on the structural property, mechanical relationships and corrosion behaviour of Inconel 718 and SS 316L dissimilar joints by TIG welding without using activated flux. J Manuf Process. 30, 290 (2017) 
26. S. Kou, Welding Metallurgy, 2nd edn. (Wiley-Interscience, Hoboken, NJ, 2003)

27. H. Nam, S. Park, E.J. Chun, H. Kim, Y. Na, N. Kang, Laser dissimilar weldability of cast and rolled CoCrFeMnNi highentropy alloys for cryogenic applications. Sci Technol Weld Join. 25, 127 (2019)

28. R. Sokkalingam, V. Muthupandi, K. Sivaprasad, K.G. Prashanth, Dissimilar welding of $\mathrm{Al}_{0.1} \mathrm{CoCrFeNi}$ high-entropy alloy and AISI304 stainless steel. J. Mater. Res. 34, 2683 (2019)

29. R. Sokkalingam, P. Mastanaiah, V. Muthupandi, K. Sivaprasad, K.G. Prashanth, Electron beam welding of high entropy alloy and stainless steel: microstructure and mechanical properties. Mater. Manuf. Process. 35, 1885 (2020)

30. D. Bridges, S. Zhang, S. Lang, M. Gao, Z. Yu, Z. Feng, A. Hu, Laser brazing of a nickel-based superalloy using a Ni-MnFe-Co-Cu high entropy alloy filler metal. Mater. Lett. 215, 11 (2018)

31. A. Eghlimi, M. Shamanian, M. Eskandarian, A. Zabolian, J.A. Szpunar, Characterization of microstructure and texture across dissimilar super duplex/austenitic stainless steel weldment joint by austenitic filler metal. Mater. Charact. 106, 208 (2015)

32. Q. Chu, R. Bai, H. Jian, Z. Lei, N. Hu, C. Yan, Microstructure, texture and mechanical properties of 6061 aluminum laser beam welded joints. Mater. Charact. 137, 269 (2018)

33. V.D. Mote, Y. Purushotham, B.N. Dole, Williamson-Hall analysis in estimation of lattice strain in nanometer-sized $\mathrm{ZnO}$ particles. J. Theor. Appl. Phy. 6, 6 (2012)

34. S. Zhou, G. Ma, D. Wu, D. Chai, M. Lei, Ultrasonic vibration assisted laser welding of nickel-based alloy and austenite stainless steel. J Manuf Process. 31, 759 (2018)

35. H.T. Wang, G.Z. Wang, F.Z. Xuan, C.J. Liu, S.T. Tu, Local mechanical properties of a dissimilar metal welded joint in nuclear power systems. Mater. Sci. Eng. A. 568, 108 (2013)

36. K. Sivaprasad, S.G.S. Raman, C.V.S. Murthy, G.M. Reddy, Coupled effect of heat input and beam oscillation on mechanical properties of alloy 718 electron beam weldments. Sci Technol Weld Join. 11, 127 (2006)
37. G.A. Knorovsky, M.J. Cieslak, T.J. Headley, A.D. Romig, W.F. Hammetter, Inconel 718: a solidification diagram. MTA 20, 2149 (1989)

38. S. Suwas, R.K. Ray, Crystallographic Texture of Materials (Springer, London, 2014)

39. H.S. Hosseini, M. Shamanian, A. Kermanpur, Microstructural and weldability analysis of Inconel 617/AISI 310 stainless steel dissimilar welds. Int. J Pres. Ves. Pip. 144, 18 (2016)

40. K. Sivaprasad, S.G.S. Raman, Influence of magnetic arc oscillation and current pulsing on fatigue behavior of alloy 718 TIG weldments. Mater. Sci. Eng. A. 448, 120 (2007)

41. H. Ming, R. Zhu, Z. Zhang, J. Wang, E.H. Han, W. Ke, M. Su, Microstructure, local mechanical properties and stress corrosion cracking susceptibility of an SA508-52M-316LN safe-end dissimilar metal weld joint by GTAW. Mater. Sci. Eng. A. 669, 279 (2016)

42. Y. Gu, C. Tao, Z. Wei, C. Liu, Microstructural evolution and mechanical properties of TIG welded superalloys GH625. Trans. Nonferrous. Met. Soc. China. 26, 100 (2016)

43. W. Wang, Y. Lu, X. Ding, T. Shoji, Microstructures and microhardness at fusion boundary of 316 stainless steel/Inconel 182 dissimilar welding. Mater. Charact. 107, 255 (2015)

44. C. Ma, J. Mei, Q. Peng, P. Deng, E.H. Han, W. Ke, Microstructure characterization of the fusion zone of an alloy 600-82 weld joint. J Mater. Sci. Technol. 31, 1011 (2015)

45. S.W. Wu, G. Wang, J. Yi, Y.D. Jia, I. Hussain, Q.J. Zhai, P.K. Liaw, Strong grain-size effect on deformation twinning of an $\mathrm{Al}_{0.1} \mathrm{CoCrFeNi}$ high-entropy alloy. Mater. Res. Lett. 5, 276 (2017)

46. A.K. Srirangan, S. Paulraj, Multi-response optimization of process parameters for TIG welding of Incoloy $800 \mathrm{HT}$ by Taguchi grey relational analysis. Eng. Sci. Technol. Int J. 19, 811 (2016)

47. G. Chandrasekar, C. Kailasanathan, M. Vasundara, Investigation on un-peened and laser shock peened dissimilar weldments of Inconel 600 and AISI 316L fabricated using activated-TIG welding technique. J Manuf Process. 35, 466 (2018) 